\title{
Reason, Authority and the Text
}

Modern thought rose out of a fierce and protracted struggle in Europe between the pre-modern religious tradition, which located ultimate truth in divine text, and a philosophical tradition which placed truth in human experience and insisted that truth could be attained through the intellectual examination of human reality. Enlightenment scholars succeeded indeed not only in defending the autonomy of rationality and reason, but also in using human intellect to develop modern social sciences.

Methodical and systematic approaches to understanding human experience propelled modern scholarship forward in its attempts to provide a better understanding of human psyche and condition. This led to the development of elaborate theories and research methods in the areas of social studies, economics, politics, psychology, administration, and others. While modern scholarship made impressive advances by using analytical reasoning to shed light on social phenomena, it hit a solid wall in its efforts to base value systems on an empirically defined rationality. Many modern scholars were initially inclined to shrug off the importance of values to social knowledge and social understanding. Some even tried to deny the transcendental nature of values. Ultimately though, the dominant positivist school was forced to give up its attempt to build human knowledge on a purely empirical basis.

The failure of modern thought to develop a purely rational scholarly tradition has emboldened postmodern writers, and encouraged them to deny the possibility of pursuing truth. Hence rationalism has been placed on an equal footing with irrationality, and morality has been equated with immorality.

\section{Power of Reason}

The intellectual impasse we all face today may be traced back to the Enlightenment scholars ' efforts to sever human values from their transcendental base, and to marginalize the importance of religious beliefs, or the lack thereof, in shaping the scholar's attitude, and in providing the transcendental presuppositions essential for social research. However, modern 
scholars have been acutely aware of the importance of religious beliefs and transcendental values for social experience: from Descartes, who insisted that the notion of God was the most fundamental notion of human understanding, to Rousseau, who underscored the desirability of a civic religion, to Kant, who thought that all moral acts presuppose a belief in human accountability before divine justice, to Hegel, who stressed that social experiences are rooted in ethical life.

Yet, they all felt compelled to deny the relevance of religion and religious sources for human understanding and knowledge, and they were all determined to establish the autonomy of human reason. We eventually came full circle to realize today, thanks to post-modern thinkers, that truth lies ultimately in meanings derived from authoritative texts.

\section{Authority of the Text}

The post-modern critique of modernism is, in many ways, a revolt against the latter's efforts to elevate historically- and culturally-specific forms of reason to the level of universal truth. Rejecting the tyranny of modern rationality, post-modernism adopted the opposite extreme by diluting the very notion of reason and truth, and hence it threatens to replace modern order with post-modern chaos.

Is there then any way out of the current impasse?

Classical Islamic scholarship seems to suggest an alternative approach to knowledge and truth, whereby reason and received texts do not negate each other, and none can claim final authority. Classical Muslim scholars realized that all texts, including the revealed text, need interpretation. Since all normative systems are ultimately rooted in a religious text of sorts, rejecting the relevance of religious sources to social knowledge is both arbitrary and deceptive. A more methodical approach requires the recognition of the necessity of rooting the transcendental presuppositions of scholarly knowledge in divine text, and the systematization of all knowledge in a rational discourse.

That is, claims about what is socially desirable cannot be made by provoking the authority of the revealed text, but by illustrating the internal cohesiveness and external consistency of all normative systems that are embedded in authoritative sources. All claims to transcendental truth must be mediated by rational arguments. This allows a plurality of truth claims without doing away with the possibility of pursuing higher Truth, and without stifling meaningful exchange and dialogue among competing systems. 


\section{Transcendental Rationality}

To avoid lapsing into the realm of irrationality and intellectual tribalism, it is imperative that transcendental values and metaphysical suppositions be openly acknowledged and straightforwardly attributed to their religious sources. This would not only make a fresh beginning for an unapologetic intellectualism, but could potentially redirect intellectual progress away from the track of irrationality and moral chaos. As long as religiously discovered truth is defended through rational argumentation, the possibility of falling back into absolutism remains far removed.

While the approach alluded to above may, understandably, create unease among those whose exposure to intellectual traditions is limited to those of western Europe, Muslim intellectuals in particular could take comfort in the long Muslim tradition in which science and rationality thrived by asserting, rather than denying, the centrality of divine revelation to human life and thought. Muslim intellectuals and scholars are particularly obligated to provide the leadership needed to reconcile intellectual tradition with a modern human consciousness that is increasingly yearning for meaning and value.

Louay M. Safi

Editor 